\title{
Application and development of stainless steel reinforced concrete
}

\section{structure}

\author{
Xian Hong MENG ${ }^{1, a}$,Si Yuan ZHANG ${ }^{1}$ \\ ${ }^{1}$ Department of Civil Engineering, Shenyang Jianzhu University, Shenyang ,China
}

\begin{abstract}
Now reinforced concrete structure in our country develops very fast, and reinforced concrete structure has been widely applied by various buildings.But with the deepening of the research experts and scholars, theyfound in some areas where high corrosion of reinforced concrete structure with the increase of service time,the concrete cracks, and led to the internal steel bar corrosion conditions.In the face of these problems, the experts used stainless steel applied to the study of concrete.In this paper,the stainless stell reinforced concrete structure of the application and development status of made briefly.
\end{abstract}

\section{Research background}

Since the reinforced concrete structure in the actual engineering application, its durability has become one of the major problems in the structure engineering, especially in the coastal areas and high corrosive areas, railway bridge and highway bridge, and so on serious erosion degree of the reinforced concrete structure. Due to construction in these areas is affected by the environment corrosion, lead to corrosion of rebar in reinforced concrete structures, with the extension of time, the corrosion of reinforcement is more and more serious, leading to the expansion of rebar in reinforced concrete, the concrete cover off, makes the steel skeleton is exposed to the air, it also accelerated the further corrosion of steel bar, not only appearance affected, and greatly reduce the bearing capacity and durability of the reinforced concrete, reduces the service life of structures. Reinforcement corrosion in reinforced concrete structures has caused the world very big economic loss ${ }^{[1]}$.

In Europe, Japan and so on some countries of the rapid development of construction industry has been studied the stainless steel, and stainless steel bar in reinforced concrete structure with steel. Stainless steel reinforcement in the Marine environment and a series of easy corrosion area and service life of bridge in $75 \sim 100$ years of engineering and the key node replaced as ordinary steel reinforced concrete with steel has received recognition of the industry, and has been widely used in large area.

\section{Introduction of stainless steel bars}

Stainless steel is a kind of stable performance and superior corrosion resistance of metal materials. Using stainless steel instead of carbon steel can improve the durability of reinforced concrete structure, can largely improve the corrosion of the steel. Stainless steel is mainly for chromium and nickel alloy components, ithas a high chemical stability, can generate dense in oxidizing medium toughness of more than $11.7 \%$ when the content of chromium passivation membrane, can make the alloy electrode potential increased significantly, effectively to prevent further oxidation of the alloy, nickel in the chrome steel, can improve the corrosion resistance of alloy in the oxidation of the medium, when the chromium, nickel content must lower carbon content in steel, the corrosion resistant performance is good.

Stainless steel according to the microstructure of different can be divided into: austenite size steel, ferritic steel, martensite steel, two-way stainless steel and precipitation hardening stainless steel. According to the different chemical composition can be divided into: ferrite series, markov system. Normally, in the stainless steel reinforced concrete structure and the types

${ }^{\mathrm{a} C}$ Corresponding author: 1445827503@qq. com 
of stainless steel is adopted in the bi-directional austenitic stainless steel and stainless steel reinforcement. The serial number of different countries on the stainless steel is different, as shown in table 1.1.

Table 1.1 stainless steel bars in the world (part) ${ }^{[2]}$

\begin{tabular}{|c|c|c|c|c|c|c|c|}
\hline \multirow{2}{*}{ No. } & \multirow{2}{*}{ Chinese number } & \multirow{2}{*}{$\begin{array}{c}\text { Japanese } \\
\text { number }\end{array}$} & \multicolumn{2}{|c|}{ The United States } & \multirow{2}{*}{$\mathbf{E U}$} & \multirow{2}{*}{ Australia } & \multirow{2}{*}{ Taiwan } \\
\hline & & & ASTM & UNS & & & \\
\hline 1 & $12 \mathrm{Cr} 17 \mathrm{Mn} 6 \mathrm{Ni} 5 \mathrm{~N}$ & SUS201 & 201 & S20100 & 1.4372 & $201-2$ & 201 \\
\hline 2 & $12 \mathrm{Cr} 18 \mathrm{Mn} 9 \mathrm{Ni} 5 \mathrm{~N}$ & SUS202 & 202 & S20200 & 1.4373 & - & 202 \\
\hline 3 & $12 \mathrm{Cr} 17 \mathrm{Ni} 7$ & SUS301 & 301 & $\mathrm{~S} 30100$ & 1.4319 & 301 & 301 \\
\hline 4 & 06Cr19Ni10 & SUS304 & 304 & S30400 & 1.4301 & 304 & 304 \\
\hline 5 & 022Cr19Ni10 & SUS304L & $304 \mathrm{~L}$ & S30403 & 1.4306 & $304 \mathrm{~L}$ & $304 \mathrm{~L}$ \\
\hline 6 & 06Cr19Ni10N & SUS304N1 & $304 N$ & S30451 & 1.4315 & $304 \mathrm{~N} 1$ & $304 \mathrm{~N} 1$ \\
\hline 7 & $06 \mathrm{Cr} 19 \mathrm{Ni} 9 \mathrm{NbN}$ & SUS304N2 & XM21 & S30452 & - & $304 \mathrm{~N} 2$ & $304 \mathrm{~N} 2$ \\
\hline 8 & $022 \mathrm{Cr} 19 \mathrm{Ni} 10 \mathrm{~N}$ & SUS304LN & $304 \mathrm{LN}$ & S30453 & - & $304 \mathrm{LN}$ & $304 \mathrm{LN}$ \\
\hline 9 & 06Cr17Ni12Mo2 & SUS316 & 316 & S31600 & 1.4401 & 316 & 316 \\
\hline 10 & 06Cr17Ni12Mo2Ti & SUS316Ti & $316 \mathrm{Ti}$ & S31635 & 1.4571 & $316 \mathrm{Ti}$ & $316 \mathrm{Ti}$ \\
\hline 11 & 022Cr17Ni12Mo2 & SUS316L & $316 \mathrm{~L}$ & S31603 & 1.4404 & $316 \mathrm{~L}$ & $316 \mathrm{~L}$ \\
\hline 12 & 06Cr17Ni12Mo2N & SUS316N & $316 \mathrm{~N}$ & S31651 & - & $316 \mathrm{~N}$ & $316 \mathrm{~N}$ \\
\hline 13 & $022 \mathrm{Cr} 17 \mathrm{Ni} 13 \mathrm{Mo} 2 \mathrm{~N}$ & SUS316LN & $316 \mathrm{LN}$ & S31653 & 1.4429 & $316 \mathrm{LN}$ & $316 \mathrm{LN}$ \\
\hline \multicolumn{8}{|c|}{ Austenitic, ferritic stainless steel (duplex stainless steel) } \\
\hline 14 & 0Cr26Ni5Mo2 & SUS329J1 & 329 & S32900 & 1.4477 & 329J1 & 329J1 \\
\hline 15 & 00Cr18Ni5Mo3Si2 & SUS329J3L & - & S31803 & 1.4462 & $329 J 3 \mathrm{~L}$ & $329 J 3 \mathrm{~L}$ \\
\hline \multicolumn{8}{|c|}{ Ferritic stainless steel } \\
\hline 16 & $0 \mathrm{Crl} 3 \mathrm{Al}$ & $06 \mathrm{Crl3Al}$ & SUS405 & 405 & $\mathrm{~S} 40500$ & STS405 & 1.4002 \\
\hline 17 & - & $022 \mathrm{Cr} 11 \mathrm{Ti}$ & SUH409 & 409 & S40900 & STS409 & 1.4512 \\
\hline 18 & $00 \mathrm{Cr} 12$ & $022 \mathrm{Cr} 12$ & SUS410L & - & - & STS410L & - \\
\hline 19 & $1 \mathrm{Cr} 17$ & $10 \mathrm{Cr} 17$ & SUS430 & 430 & S43000 & STS430 & 1.4016 \\
\hline
\end{tabular}

\section{Application of stainless steel reinforced concrete structure}

The first high stainless steel reinforced concrete engineering is completed in 1941 ,it is Mexican Yucatan Progress pile foundation engineering of the port $^{[3]}$.The project usedthe model 304 stainless steel bar.Although during the period of construction cost more expensive compared with the ordinary steel, in the project is still not repaired, the corrosion in Marine environment

Table 1.2 examples of foreign stainless steel reinforced concrete structures ${ }^{[4]}$

\begin{tabular}{ccc}
\hline The Bridges & Stainless steel type & Weight \\
\hline The Brooklyn bridge in New York & 2205 & 181 吨 \\
New Jersey Garden State Parkway the highway bridge & 2205 & 165 吨 \\
Oregon Haynes Inlet Slough bridge & 2205 & 400 吨 \\
Canada Church bridge & $316 \mathrm{LN}$ & 150 吨 \\
British Cradlewell underground passage & 316 & 240 吨 \\
London's Guildhall Yard Eastproject & 304 & 140 吨 \\
The uae Sheik zayed bridge & EN 1.4462 & -
\end{tabular}

In our country, the AngChuan Zhou Bridgeis firstly made of stainless steel reinforcement project, the project adopts the stainless steel reinforced with a magnitude of 1.4462 types of stainless steel.Due to the bridge design to take into account the project cost and actual application effect, only the outermost layers of reinforcement in bridge components and prone to corrosion of bridge node adopts the stainless steel reinforced.ShenzhenWestern Corridor Bridge, the bridge length $3.2 \mathrm{~km}$, in the design of the bridge, designers considered the construction cost and the actual application effect, adopted a diameter of $16 \mathrm{~mm}$ to $40 \mathrm{~mm} \mathrm{S31600} \mathrm{(JIS316)}$ completed still maintain good state of service.Up to now,inmarine corrosive environment still maintain good state of service, and built in 1963 near the project of ordinary concrete piles have been serious corrosion phenomena.It can prove that in the long run, the high stainless steel instead of stainless steel rebar corrosion area has obvious economic benefits and remarkable achievement. Table 1.2 is abroad some stainless steel reinforcement in practical engineering instance.

and S2205 two types of stainless steel as part of the bridge reinforcement, the rest for ordinary reinforced still adopted ordinarysteel, this would make it easier for Western Corridor Bridge not for large servicing within 120.Hong kong-Zhuhai-Macao Bridge is the most used stainless steel to reinforced concrete engineering amount of the project, the project costs the most expensive in the world, construction difficulty is the largest and longest span of the project.Hongkong-zhuhai-macao bridge using the duplex stainless steel rebar is made by shanxitaigang group independent research and development.Stainless steel is mainly used in the 
bearing platform for part of the hongkong-zhuhai-macao bridge which is easy to rust, the bridge is about 50 kilometers long, the dosage of the stainless steel 3500 tons.

\section{The research status of stainless steel reinforced concrete structure}

In recent years our country studies the mechanics properties of stainless steel bar:

In 2007, GuoxueZhang YongshengXu, in order to observe the specimen of crack width and deflection, the ultimate bearing capacity index, analyzing the mechanical properties of stainless steel reinforced concrete beam, design of the stainless steel reinforced concrete beam static load experiment. Experimental results demonstrate in the use of stainless steel reinforced concrete beam phase, the maximum crack width and the maximum deflection are within the scope of ordinary reinforced concrete design value. If using ACI American code of reinforced concrete beam deflection formula to calculate and compare the data and found stainless steel reinforced concrete beam specimen deflection and the whole loading process of specimen are closer to the actual situation of deflection.

In 2008, Wu miaomiao made 27 a study to test adhesive strength of pull-out tests to study the bond strength of reinforced concrete stainless steel. Test results show that, the stainless steel bond strength of reinforced concrete and ordinary reinforced concrete in the steel surface shape under the condition of identical is roughly same, so you can choose ordinary steel instead of stainless steel reinforcement design calculation anchorage length.

In 2010, Guo-xueZhang do the stainless steel reinforced concrete beam subjected to low-cyclic static test, they focus on the types of strength grade of concrete, steel bar, stirrup ratio and so on several factors. The results showed that the stainless steel reinforced concrete beam specimens of various performance including limit displacement, yield displacement and displacementductility coefficient is significantly higher than that of ordinary reinforced concrete specimen, such as limit displacement, yield displacement and displacement ductility coefficient.

In 2012, Chang-weiWang established the parameters formula of the stainless steel reinforced concrete column.This formula was established by using nonlinear program ensees simplifies the model of restoring force of the stainless steel reinforced concrete column and get, and explore the stainless steel reinforced concrete column under constant load under the model of hysteresis. Finally, through the contrast analysis, the original application of theoretical calculation and experimental result is close to the curve.

In 2013, Gary huangtry to do fatigue test, analysis the various performance betweenthe stainless steel reinforced concrete beam and ordinary reinforced concrete beams, including beam crack width and the development status, stress on cycle times, the relationship between stress and strain of steel bar and reinforced concrete, in order to study the various characteristics of stainless steel reinforced concrete beam.

Foreign scholars mainly study the stainless steel corrosion resistance:

Zelbel $^{[5]}$ did the reinforcement corrosion test, ordinary carbon steel reinforced concrete specimens respectively and is equipped with stainless steel specimen comparison study, through the concrete corrosion damage of the specimens tested the applicability of the stainless steel reinforcement in concrete structures. Experimental results show that the ordinary carbon steel concrete specimen crack due to reinforcement corrosion, but stainless steel concrete specimen without any crack. Damage reason is summarized as: volume of reinforcement corrosion in reinforced concrete, increasing the extrusion to produce ring tensile stress, when reach ultimate tensile strain of concrete fracture, and cracks, the internal corrosion of steel bar is more likely to be accelerated concrete destruction.

Cox and Flint ${ }^{[6]}$ respectively put normal deformation of reinforced concrete specimen, solid stainless steel reinforced concrete specimen and stainless steel in seawater to analysis of observation, concluded that the corrosion resistance of stainless steel is very strong, the strength of the steel bar did not drop by, the surface of the steel is not corroded; Equipped with ordinary reinforced concrete cracks and steel bar intensity drops, steel surface corrosion is serious.

Nye and others put stainless steel reinforced concrete specimens in relatively normal atmospheric environment, the chloride ion corrosion resistance experiment was carried out. Using different kinds of stainless steel compared with ordinary reinforced concrete specimens, the purpose was to observe the damage of concrete block. Test conclusion: the common concrete cracks, the specimens reinforced corrosion occur; And stainless steel specimens without corrosion phenomenon, no cracks, also found in terms of corrosion resistance, corrosion resistance of austenitic stainless steel is better than other types of the corrosion resistance of stainless steel.

The domestic and international numerous stainless steel corrosion test results show that the 
stainless steel reinforced under the serious environmental corrosion factors can maintain good physical properties and chemical properties, has a superior corrosion resistance.

\section{Conclusion}

The corrosion problem of the ordinary reinforced concrete engineering is the important research direction of scholars, using stainless steel instead of common steel can effectively solve the problem of rust.Although in the project cost be more expensive than ordinary steel, is applied to some engineering structures or important buildings, can guarantee in many years, can need not big repair, so in the long run, it is very suitable.

\section{Acknowledgements}

This work is financially supported by National High-tech R\&D Program Program)(2015AA03A502-3).

\section{References}

1. ABDULLAH A, ALMUSALLAM.Effect of degree of corrosion on the properties of reinfarcaig steel bars, Construction and Buildaig Material.J.2007, 15(8): 361-68

2. GB/T 1220-2007, The stainless steel rod.S

3. Zhang Xiaojuan. Study on the corrosion inhibition effect of aluminum zinc layered double metal hydroxide and its derivatives on reinforced concrete. Xiamen: Xiamen University. D.2010.

4. Huang Jiawei. Experimental research on fatigue performance of [D]. steel reinforced concrete bridge girder.2013. Guangzhou: Guangdong University of Technology

5. E.Mirambell, E.Real. On the calculation of deflection in structural stainless steel beams: an experimental andnumericalinvestigation.JournalofConstr uctionalSteelResearch, J.2000,54(1):109-133.

6. Zin-Taek Park, Yoon-Seok Choi, Jung-Gu Kim and Lan hung. Development of a galvanic sensor system for detecting the corrosion damage of the steel embedded in concrete structure.Cement and Concrete

Research, J.2005,35(9):1814-1819. 